\title{
Effect of Induced Charge on the Passivity and Passivity Breakdown of 304LN Stainless Steels
}

\author{
Gargi Roy Chowdhury and P. K. Mitra \\ Department of Metallurgical and Material Engineering, Jadavpur University, Kolkata 700 032, India \\ Correspondence should be addressed to Gargi Roy Chowdhury, roychowdhurygargi@gmail.com
}

Received 16 March 2011; Revised 28 April 2011; Accepted 8 June 2011

Academic Editor: Luigi Nicolais

Copyright ( $) 2011$ G. Roy Chowdhury and P. K. Mitra. This is an open access article distributed under the Creative Commons Attribution License, which permits unrestricted use, distribution, and reproduction in any medium, provided the original work is properly cited.

\begin{abstract}
Passivity breakdown of stainless steel by pitting in chloride environment is believed to occur at point at zero charge (pzc). So, the nature and quantity of charge on the surface plays a very important role on the breakdown of passivity, as chloride ion adsorption depends on that. In this work a DC potential was maintained between aluminium and graphite electrodes, and the aluminium electrode, in turn, was kept in the vicinity of the working electrode in the potentiostatic circuit. Both positive and negative polarity was applied on aluminium to attract or repel chloride ions in the vicinity of the working electrode. Chloride adsorption pattern on the stainless steel electrode got drastically altered due to application of DC potential on the aluminium-graphite circuit.
\end{abstract}

\section{Introduction}

Stainless steel finds wide applications in industrial as well as nuclear reactors because of excellent corrosion resistance property. The mechanism that slows down corrosion in these materials is termed as "passivity". For the majority of the metals and alloys that exhibit active passive transition, passivity is based on the spontaneous formation of a thin oxide layer, in a specific environment [1]. This film slows down corrosion reactions by many orders of magnitude. The nature and composition of passive films formed on stainless steels, and especially their protective nature, are dependent on the formation conditions. Stable passive films formed on alloys with compositions close to 304 stainless steels are heterogeneous. These films are described by a bilayer structure composed essentially of a chromium hydroxide, $\mathrm{Cr}(\mathrm{OH})_{3}$, outer layer, and a mixed inner layer of chromium and iron oxides, enriched in chromium. This structure is similar to that produced on passivated ferritic ironchromium alloys [2].

It is well known that passive films formed on metals in the presence of chloride ions are less stable due to local damage and pitting corrosion. The penetration effect and pitting by $\mathrm{Cl}^{-}$depends on many factors. The incorporation of anions such as $\mathrm{SO}_{4}{ }^{2-}$ leads to further growth of barrier layer as well as impeding the ingress of $\mathrm{OH}^{-}$and $\mathrm{Cl}^{-}$ ions. Passivity breakdown of stainless steel by pitting in chloride environment is believed to occur at pzc which is known as point of zero charge, at which there will be no electrostatic fixed charge on the surface of the sample. During electrochemical passivation in electrolyte containing $\mathrm{Cl}^{-}$ions, below pzc, there are negative charges on the oxide surface through which a few $\mathrm{Cl}^{-}$ions contact adsorb [3]. With increase in polarized potential the passive layer breaks down at a potential called pitting potential [4]. At this potential, there is no charge on the surface. At potentials higher than this, there is positive charge on the oxide surface, this in turn attract the $\mathrm{Cl}^{-}$ions and current increases, causing pitting corrosion [5].

In this work, an attempt of reducing pitting corrosion has been done by inducing electrostatic charges. It has been obtained by using a metal foil in the vicinity of the stainless steel. If the foil is positively charged, it will induce fixed electrostatic negative charge on the stainless steel, and it is expected that the negative ions would get attracted to it thereby reducing pitting of the stainless steel. The nature of electrochemical passivity of the stainless steel was studied by potentiostatic polarization with the application of DC potential in the aluminium foil-graphite circuit. 
TABLE 1: Composition of 304LN stainless steel.

\begin{tabular}{lccccccccc}
\hline Component & $\mathrm{C}$ & $\mathrm{Mn}$ & $\mathrm{Si}$ & $\mathrm{P}$ & $\mathrm{S}$ & $\mathrm{Cr}$ & $\mathrm{Ni}$ & $\mathrm{N}$ & $\mathrm{Fe}$ \\
\hline$\%$ & 0.08 & 2.0 & 0.75 & 0.045 & 0.03 & 18.0 & 10.5 & 0.2 & Balance \\
\hline
\end{tabular}

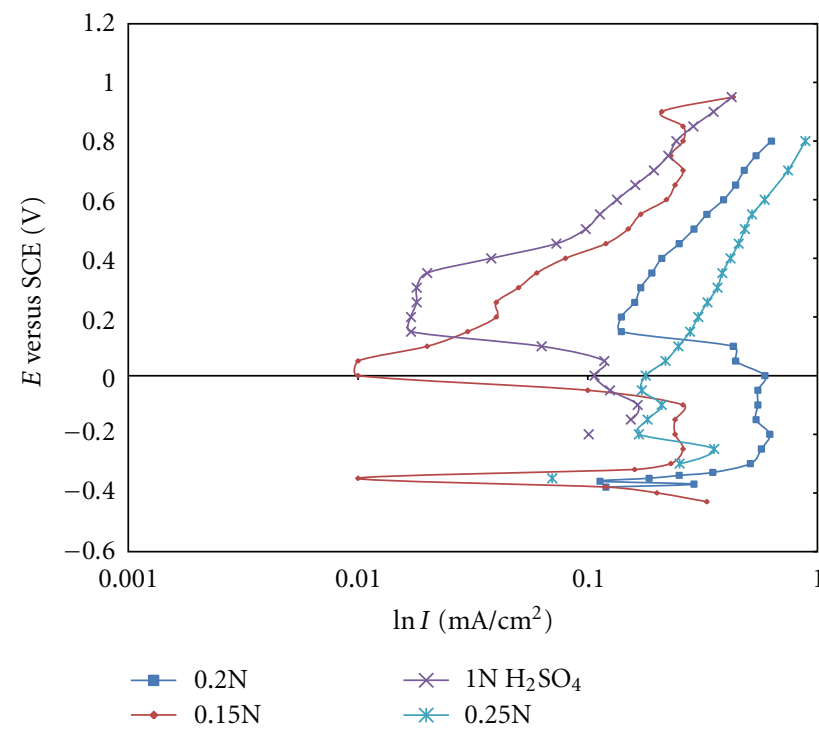

FIGURE 1: Polarization diagram in different chloride ion containing $1 \mathrm{~N} \mathrm{H}_{2} \mathrm{SO}_{4}$.

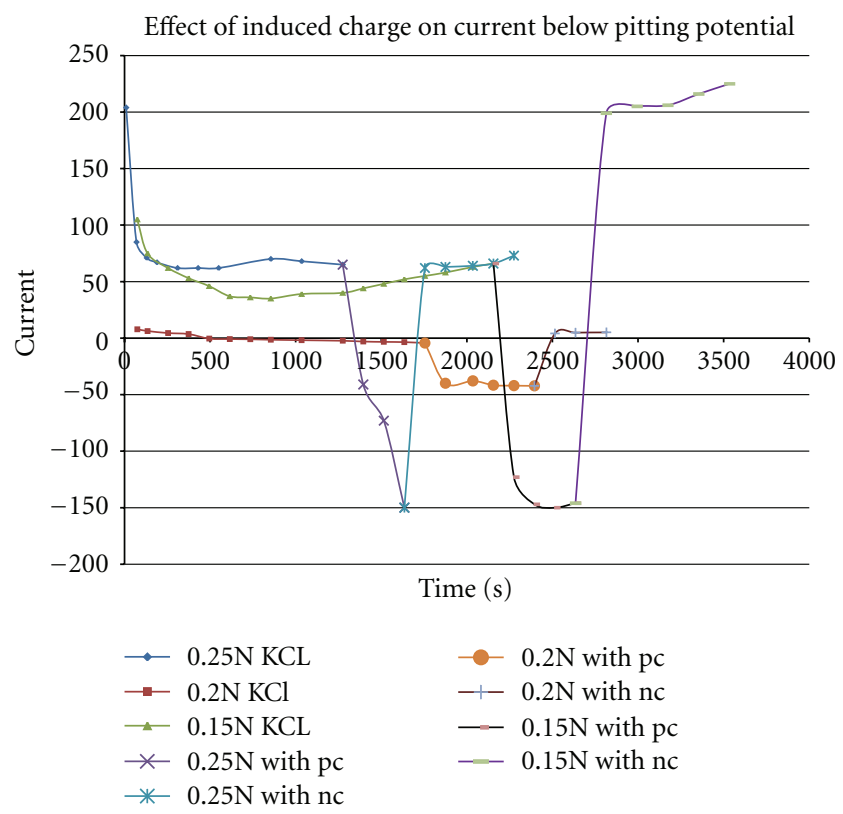

FIgURe 2: Current transient below the pitting potential with and without induced charge in various chloride solutions.

The passivated samples under the influence of the DC potential in the external circuit were further characterized by potentiodynamic polarization, EIS, and SEM/EDAX. The corrosion properties in different chloride concentration with and without charge were compared.

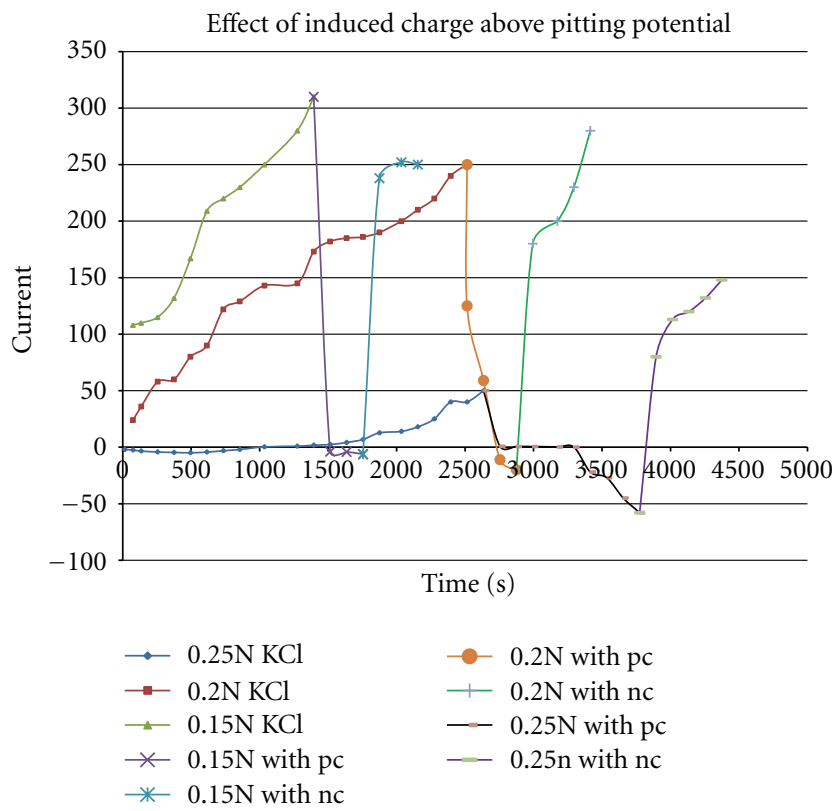

FIGURE 3: Current transient above the pitting potential with and without induced charge in various chloride solutions.

TABLE 2: Polarization data from the polarization diagrams.

\begin{tabular}{lcc}
\hline $\begin{array}{l}\text { Chloride } \\
\text { concentration }\end{array}$ & Pitting potentials & $\begin{array}{c}\text { Passive current } \\
\text { density }\left(\mathrm{mA} / \mathrm{cm}^{2}\right)\end{array}$ \\
\hline $0.15 \mathrm{~N}$ & $0.25 \mathrm{~V}$ & $0.01-0.04$ \\
$0.2 \mathrm{~N}$ & $0.2 \mathrm{~V}$ & $0.14-0.15$ \\
$0.25 \mathrm{~N}$ & $0.05 \mathrm{~V}$ & $0.007-0.02$ \\
\hline
\end{tabular}

\section{Experimental}

2.1. Specimen Preparation. The composition of the 304LN stainless steel sample is given in Table 1. Flat surface of short cylindrical samples were polished mechanically to a mirror finish using successive grades of emery papers, namely, $180,120,1 / 0$, and $2 / 0$ followed by cloth polishing with alumina powder. Then the specimens were washed thoroughly with distilled water, degreased with acetone properly for 15 minutes, cleaned with alcohol, and inspected if any pits are there or not, and then transferred quickly into the electrochemical cell. Then, the sample was masked with Teflon so that only the flat surface of the steel touched the solution when dipped in it.

2.2. Electrochemical Measurements. Standard corrosion cell was used to perform the electrochemical passivity and polarization tests on standard flat metal specimens. Polarization experiments were carried out using a standard Potentiostat, 
TABLE 3: Corrosion data with and without induced charge below pitting potential.

\begin{tabular}{lcc}
\hline Sample & $E_{\mathrm{CORR}}\left(V_{\mathrm{SCE}}\right)$ & $I_{\mathrm{CORR}}\left(\mathrm{mA} / \mathrm{cm}^{2}\right)$ \\
\hline Without charge in $0.15 \mathrm{~N} \mathrm{KCl}$ solution & -0.25 & 0.19 \\
With positive charge in $0.15 \mathrm{~N} \mathrm{KCl}$ solution & -0.2 & 0.19 \\
With negative charge in $0.15 \mathrm{~N} \mathrm{KCl}$ solution & -0.2 & 0.24 \\
Without charge in $0.2 \mathrm{~N} \mathrm{KCl} \mathrm{solution}$ & -0.41 & 0.27 \\
With positive charge in $0.2 \mathrm{~N} \mathrm{KCl}$ solution & -0.4 & 0.23 \\
With negative charge in $0.2 \mathrm{~N} \mathrm{KCl}$ solution & -0.4 & 0.3 \\
Without charge in $0.25 \mathrm{~N} \mathrm{KCl} \mathrm{solution}$ & -0.38 & 0.28 \\
With positive charge in $0.25 \mathrm{~N} \mathrm{KCl}$ solution & -0.35 & 0.26 \\
With negative charge in $0.25 \mathrm{~N} \mathrm{KCl}$ solution & -0.3 & 0.29 \\
\hline
\end{tabular}

TABLE 4: Corrosion data with and without induced charge above pitting potential.

\begin{tabular}{lcc}
\hline Sample & $E_{\mathrm{CORR}}\left(V_{\mathrm{SCE}}\right)$ & $I_{\mathrm{CORR}}\left(\mathrm{mA} / \mathrm{cm}^{2}\right)$ \\
\hline Without charge in $0.15 \mathrm{~N} \mathrm{KCl}$ solution & -0.25 & 0.23 \\
With positive charge in $0.15 \mathrm{~N} \mathrm{KCl}$ solution & -0.35 & 0.28 \\
With negative charge in $0.15 \mathrm{~N} \mathrm{KCl}$ solution & -0.35 & 0.42 \\
Without charge in $0.2 \mathrm{~N} \mathrm{KCl} \mathrm{solution}$ & -0.4 & 0.49 \\
With positive charge in $0.2 \mathrm{~N} \mathrm{KCl}$ solution & -0.36 & 0.38 \\
With negative charge in $0.2 \mathrm{~N} \mathrm{KCl}$ solution & -0.3 & 0.62 \\
Without charge in $0.25 \mathrm{~N} \mathrm{KCl} \mathrm{solution}$ & -0.35 & 0.61 \\
With positive charge in $0.25 \mathrm{~N} \mathrm{KCl}$ solution & -0.25 & 0.3 \\
With negative charge in $0.15 \mathrm{~N} \mathrm{KCl}$ solution & -0.3 & 0.68 \\
\hline
\end{tabular}

TABLE 5: EIS data in $0.15 \mathrm{~N} \mathrm{KCl}$ solution.

\begin{tabular}{lcccc}
\hline Samples & $R_{P}$ values & $R_{u}$ values & $Y_{o}$ & Alpha \\
\hline $\begin{array}{l}\text { Below pitting potential } \\
\text { without charge }\end{array}$ & $2.596 e 3$ & 1.796 & $385.0 e-3$ & $653.8 e-36$ \\
$\begin{array}{l}\text { Below pitting potential with } \\
\text { positive charge }\end{array}$ & $3.434 e 3$ & 2.891 & $340.4 e-3$ & $714.7 e-3$ \\
$\begin{array}{l}\text { Below pitting potential with } \\
\text { negative charge }\end{array}$ & $1.767 e-3$ & 2.620 & $610.1 e-6$ & $591.8 e-3$ \\
$\begin{array}{l}\text { Above pitting potential } \\
\text { without charge }\end{array}$ & 721.6 & 2.100 & $215.9 e-6$ & $711.9 e-3$ \\
$\begin{array}{l}\text { Above pitting potential with } \\
\text { positive charge }\end{array}$ & 964.97 & $122.6 \mathrm{e}-6$ & $101.8 e-18$ & 4.825 \\
$\begin{array}{l}\text { Below pitting potential with } \\
\text { negative charge }\end{array}$ & $1.451 e-3$ & 2.275 & $347.7 e-6$ & $\mathrm{CPE}$ \\
\hline
\end{tabular}

TABLE 6: EIS data in $0.2 \mathrm{~N} \mathrm{KCl}$ solution.

\begin{tabular}{|c|c|c|c|c|c|}
\hline Samples & $R_{P}$ values & $R_{u}$ values & $Y_{o}$ & Alpha & Model type \\
\hline $\begin{array}{l}\text { Below pitting potential } \\
\text { without charge }\end{array}$ & $4.372 e 3$ & 2.671 & $2.48 .5 e-6$ & $678.7 e-3$ & $\mathrm{CPE}$ \\
\hline $\begin{array}{l}\text { Below pitting potential with } \\
\text { positive charge }\end{array}$ & $5.103 e 3$ & 2.499 & $345.1 e-6$ & $662.8 e-3$ & CPE \\
\hline $\begin{array}{l}\text { Below pitting potential with } \\
\text { negative charge }\end{array}$ & $2.926 e 3$ & 2.425 & $371.7 e-6$ & $643.0 e-3$ & $\mathrm{CPE}$ \\
\hline $\begin{array}{l}\text { Above pitting potential } \\
\text { without charge }\end{array}$ & $1.553 e 3$ & 2.493 & $434.9 e-6$ & $623.8 e-3$ & $\mathrm{CPE}$ \\
\hline $\begin{array}{l}\text { Above pitting potential with } \\
\text { positive charge }\end{array}$ & $6.808 e 3$ & $572.6 e-3$ & $325.5 e-6$ & $652.3 e-3$ & $\mathrm{CPE}$ \\
\hline $\begin{array}{l}\text { Below pitting potential with } \\
\text { negative charge }\end{array}$ & 888.8 & 2.838 & $648.2 e-6$ & $561.6 e 3$ & $\mathrm{CPE}$ \\
\hline
\end{tabular}


TABLE 7: EIS data in $0.25 \mathrm{~N} \mathrm{KCl}$ solution.

\begin{tabular}{lcccc}
\hline Samples & $R_{P}$ values & $R_{u}$ values & $Y_{o}$ & Alpha \\
\hline $\begin{array}{l}\text { Below pitting potential } \\
\text { without charge }\end{array}$ & 764.9 & $839.2 e-3$ & $356.2 e-6$ & $646.9 e-3$ \\
$\begin{array}{l}\text { Below pitting potential with } \\
\text { positive charge }\end{array}$ & 840.9 & $471.6 e-3$ & $310.3 e-6$ & $633.0 e-3$ \\
$\begin{array}{l}\text { Below pitting potential with } \\
\text { negative charge }\end{array}$ & $1.260 e-3$ & $32.50 e-6$ & $302.0 e-6$ & $614.2 e-3$ \\
$\begin{array}{l}\text { Above pitting potential } \\
\text { without charge }\end{array}$ & 555.2 & 2.371 & $164.2 e-6$ & $748.7 e-3$ \\
$\begin{array}{l}\text { Above pitting potential with } \\
\text { positive charge }\end{array}$ & 849.2 & 4.101 & $244.5 e-6$ & $644.9 e-3$ \\
$\begin{array}{l}\text { Below pitting potential with } \\
\text { negative charge }\end{array}$ & $2.540 e-3$ & 2.735 & $271.9 e-6$ & CPE \\
\hline
\end{tabular}

TABLE 8: EDX data in $0.15 \mathrm{~N} \mathrm{KCl}$ solution.

\begin{tabular}{lccccccccc}
\hline & \multicolumn{2}{c}{$\mathrm{O}$} & \multicolumn{2}{c}{$\mathrm{Cr}$} & \multicolumn{2}{c}{$\mathrm{Cl}$} & \multicolumn{2}{c}{$\mathrm{Fe}$} \\
& $\mathrm{W} \%$ & $\mathrm{~A} \%$ & $\mathrm{~W} \%$ & $\mathrm{~A} \%$ & $\mathrm{~W} \%$ & $\mathrm{~A} \%$ & $\mathrm{~W} \%$ & 57.64 \\
\hline BWC & 10.6 & 28.33 & 16.65 & 14.42 & 0.42 & 0.53 & 47.48 \\
BPC & 10.09 & 30.87 & 18.54 & 15.76 & 0.4 & 0.5 & 63.19 \\
BNC & 6.23 & 18.62 & 19.17 & 17.64 & 0.38 & 0.51 & 65.92 & 56.46 \\
\hline
\end{tabular}

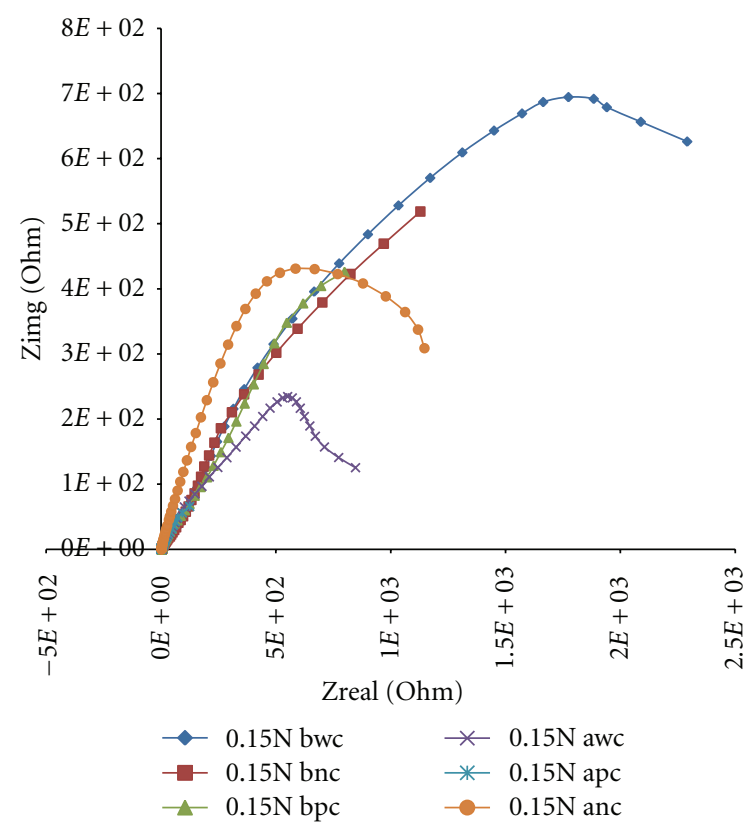

FIGURE 4: EIS curve above and below pitting potential in $0.15 \mathrm{~N} \mathrm{KCl}$ solution with and without charge.

in which all the electrochemical measurements were performed in a standard three-electrode system. Graphite was taken as counter electrode, and saturated calomel electrode was used as reference electrode.

Using quasistationary step rate of $50 \mathrm{mV} / 5$ mints, the polarization curves were obtained. All polarization experiments were done in $1 \mathrm{~N} \mathrm{H}_{2} \mathrm{SO}_{4}$ without and with different chloride concentrations. Chloride concentrations used were $0.15 \mathrm{~N}, 0.2 \mathrm{~N}$, and $0.25 \mathrm{~N}$. The polarization curves are given in

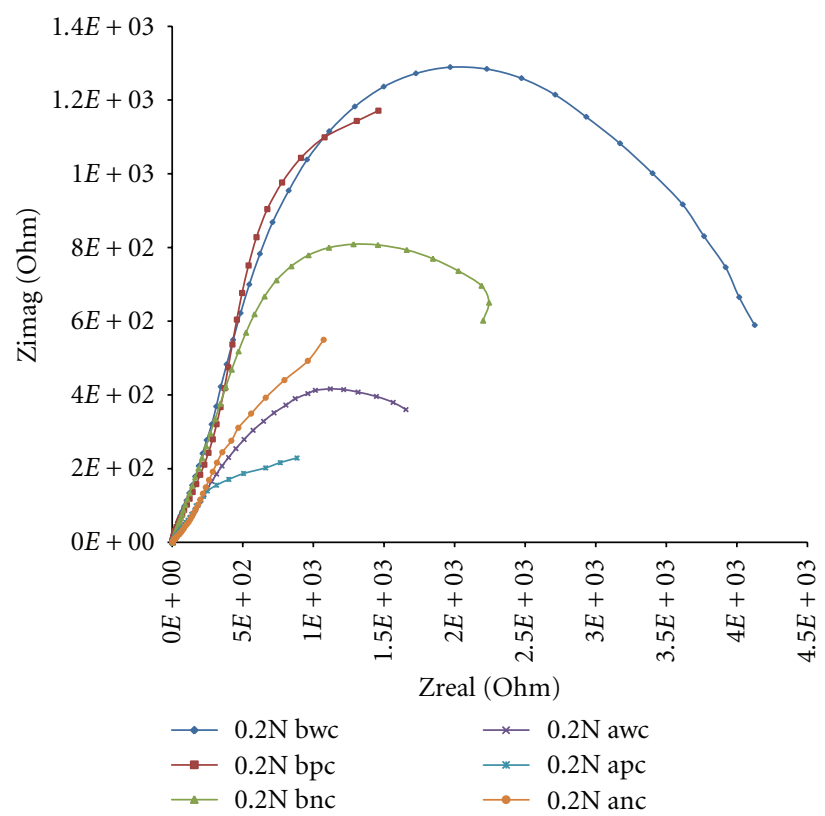

FIGURE 5: EIS curve above and below pitting potential in $0.2 \mathrm{~N} \mathrm{KCl}$ solution with and without charge.

Figure 1. Pitting potential and passive current density of the steel in the different chloride containing solutions are given in Table 2 . The $I_{\mathrm{CORR}}-E_{\mathrm{CORR}}$ values were obtained by Tafel's extrapolation method.

Fixed applied polarized potentials selected above and below the pitting potential were applied to the sample and current transient of the sample in each chloride concentration. The current transient in $0.15 \mathrm{~N}, 0.2 \mathrm{~N}$, and $0.25 \mathrm{~N}$ acidic chloride solution below the pitting potential were 
TABLE 9: EDX data in $0.25 \mathrm{~N} \mathrm{KCl}$ solution.

\begin{tabular}{lccccccccc}
\hline & \multicolumn{2}{c}{$\mathrm{O}$} & \multicolumn{2}{c}{$\mathrm{Cr}$} & \multicolumn{2}{c}{$\mathrm{Cl}$} & \multicolumn{2}{c}{$\mathrm{Fe}$} \\
& $\mathrm{W} \%$ & $\mathrm{~A} \%$ & $\mathrm{~W} \%$ & $\mathrm{~A} \%$ & $\mathrm{~W} \%$ & $\mathrm{~A} \%$ & $\mathrm{~W} \%$ & 59.47 \\
\hline AWC & 12.03 & 20.52 & 16.75 & 13.5 & 0.02 & 0.02 & 44.62 \\
APC & 8.84 & 24.66 & 18.54 & 15.92 & 0.44 & 0.55 & 61.46 \\
ANC & 8.82 & 20.61 & 18.66 & 16.02 & 0.13 & 0.16 & 61.32 & 49.12 \\
\hline
\end{tabular}

BWC: below pitting potential without charge, BPC: below pitting potential with positive charge, BNC: below pitting potential with negative charge, APC: above pitting potential with positive charge, ANC: above pitting potential with negative charge.

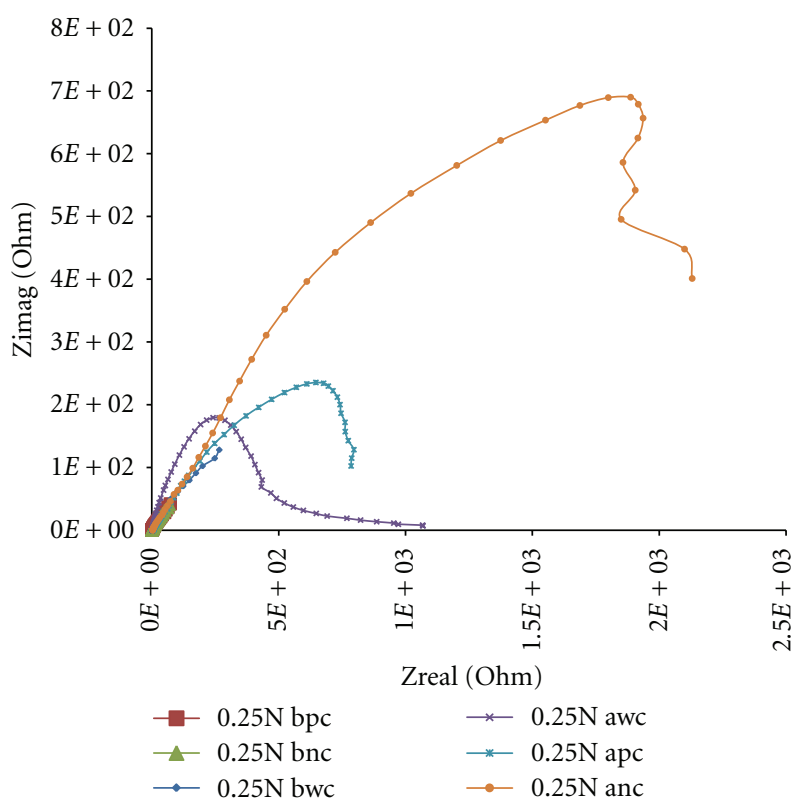

FIGURE 6: EIS curve above and below pitting potential in $0.25 \mathrm{~N} \mathrm{KCl}$ solution with and without charge.

carried out at $0.3 \mathrm{~V}, 0.2 \mathrm{~V}$, and $0.04 \mathrm{~V}$, respectively, results being shown in Figure 2. Similarly, above the pitting potential current transient were carried out at $0.35 \mathrm{~V}, 0.3 \mathrm{~V}$, and $0.05 \mathrm{~V}$, respectively until the current became stabilised, results of which are given in Figure 3.

2.3. Experiments with External Charge. The setup for applying the external charge is given in Figure 10. In the figure, other than the reference electrode, the working electrode and the counter electrode are shown with grey and black colours, respectively. For applying external charge an aluminium foil (yellow) was kept next to the working electrode in the same cell and a DC potential was applied between the aluminium foil and a separate graphite electrode (black). Current transients experiments below and above the pitting potential in different chloride containing solutions as mentioned earlier were repeated, and when the current became stable, initially a positive potential of 4 Volts was applied to the aluminium foil. A change in the current density of the working electrode was noticed. Once it stabilized, the DC potential between the aluminium foil and the graphite was reversed to negative 4 Volts. The change in the current density of the working electrode was noted. The current transients are shown in
Figures 2 and 3. The effect of the application of positive and negative potential are shown with different colours and abbreviated as with pc for positive potential and with nc for negative potential. After withdrawal of the charge, the samples were again polarized in the respective chloride bearing $1 \mathrm{~N} \mathrm{H}_{2} \mathrm{SO}_{4}$ solution and $E_{\text {CORR }}$ and $I_{\text {CORR }}$ values were estimated. While for experiments conducted below pitting potential the values are reported in Table 3, and in Table 4, results for experiments conducted above pitting potential are reported. Current transient experiments without application of external DC potentials as well as with application of external DC potentials were repeated, and after attaining respective steady state current of the working electrode in the potentiostatic circuit, the samples were withdrawn and subjected to impedance spectroscopy in the same respective solutions.

For electrochemical impedance spectroscopy measurements an AutolabPC14G300-44030 potentiostat/galvanostat, expanded with a Potsat model seriesG300 was used. The impedance experiments were carried out using $\mathrm{AC}$ voltage of $100 \mathrm{mV}$ root-mean-square and the DC voltage of $1 \mathrm{~V}$ with frequency ranged from $10 \mathrm{kHz}$ to $10 \mathrm{mHz}$ at 10 cycles per decade. The absolute impedance and phase angles were measured at each frequency. Nyquist and Bode plots were obtained. The different circuit element which can represent the interaction between a corroding metal and/or alloy and a corrosive medium can be independently categorised as follows.

(1) Coating Resistance $\left(R_{P}\right)$. In the present context, $R_{P}$ represents the resistance developed at the oxide formed on the sample due to passivation. In other words, the amount of degradation of the exposed surface in turn depends on the corresponding $R_{P}$ value. Clearly, one can conclude that higher the $R_{P}$ lower is the rate of corrosion of the exposed metal and/or alloy surface to the electrolyte.

(2) Solution Resistance $\left(R_{u}\right)$. Solution resistance is often a significant factor in the impedance of an electrochemical cell. In a bounded area with area $A$ and length $l$ carrying a uniform current, the resistance is defined as

$$
R_{u}=\frac{\rho l}{A},
$$

where $\rho$ is the solution resistivity.

In general, this $R_{u}$ depends on the nature of different ions present in the solution specially on their mobilities. 


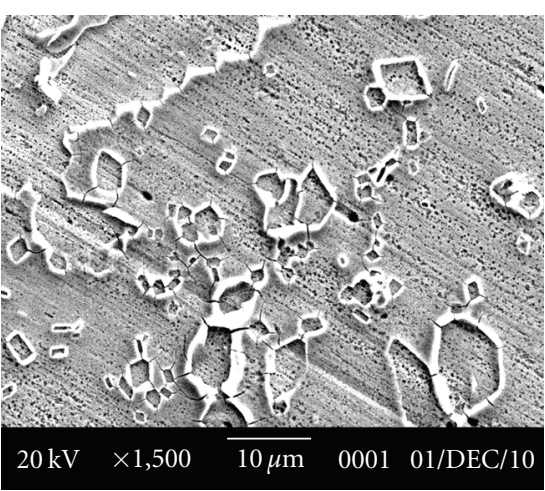

(a) Without induced charge

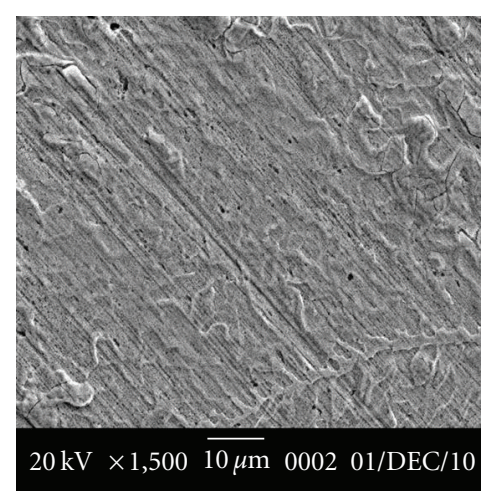

(b) With positive charge below pitting

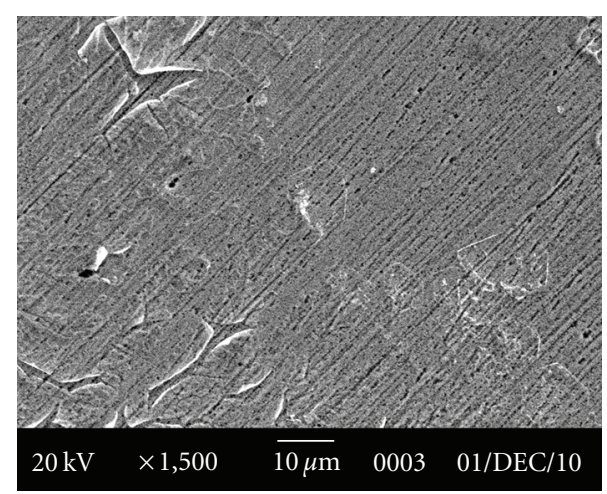

(c) With negative charge below pitting potential

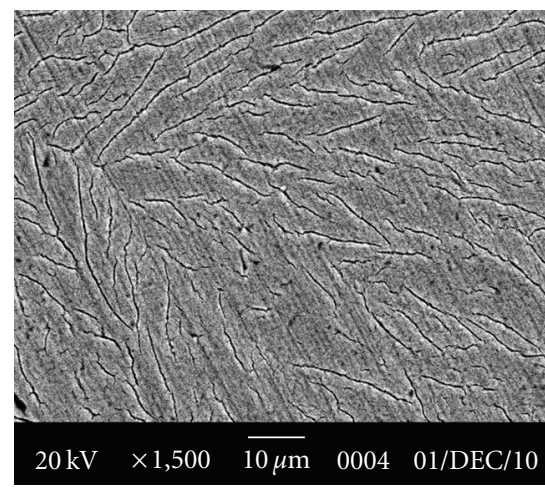

(d) With positive charge above pitting

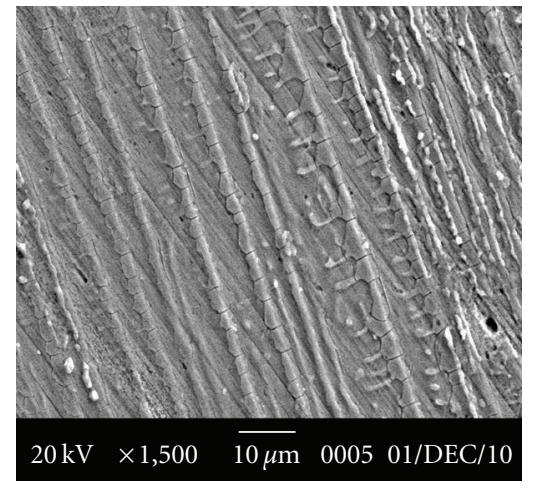

(e) With negative charge above pitting potential

FIgURE 7: SEM image in $0.15 \mathrm{~N} \mathrm{KCl}$ solution with and without induced charge.

(3) Double Layer Capacitance $\left(C_{f}\right)$. For a given applied potential to an electrode in solution, there will be a segregation of charges arising from the charge on the metal electrode and a charge in the solution due to an excess of anions or cations in the proximity of the electrode. This is known as electrical double layer and can be represented as capacitance.

(4) Admittance $\left(Y_{o}\right)$. It is the reciprocal of the solution resistance value.Since in the present context, only CPE was found from the curve fitting, it has been defined and its corresponding equivalent circuit is also given.

(5) Constant Phase Element (CPE) Model. The double-layer capacitor on real cell often behaves like a constant phase element (CPE) instead of like an ideal capacitor. Several theories have been proposed to account for the nonideal behaviour of the double layer, but none has been universally accepted.

Curve fitting was done to choose the respective models to get the rough value of all model fit parameters. From the Bode plot by rough estimation, these values were calculated. The parameters like $R_{p}, C_{f}, R_{u}, Y_{o}$, and $\alpha$ were also estimated, and the exact values of $R_{p}$ and $R_{u}$ were calculated by the Echem software. The impedance data were interpreted on the basis of equivalent electric circuit shown in Figure 11, using the Fit model (simplex model) program for fitting the experimental data. Constant phase elements were found to give perfect fitting. For 304LN EIS data obtained are given in Tables 5, 6, and 7 .

2.4. SEM and EDX Study. To understand the effect of induced charge surface characterizations of the samples were done by scanning electron microscope and energy dispersion X-ray. Surface and pit morphology by scanning electron microscope are shown in Figures 7, 8, and 9. The average chemical compositions of the passivated surface were obtained by EDX which is given in Tables 8 and 9 .

\section{Discussions}

Polarisation curve shows the passive layer and breakdown point with the increasing normality of chloride solution. The pitting potentials and the passive current density were obtained from this curve which is given in Table 2. The $E_{\text {CORR }}$ and $I_{\text {CORR }}$ values for with and without external charge also obtained from the polarisation curve by Tafel's extrapolation plot as given in Tables 3 and 4 . The change in $I_{\text {CORR values }}$ maybe explained as the experiment has been carried out after withdrawing charges, so it is expected that the effect of electrostatic charges are not there. 


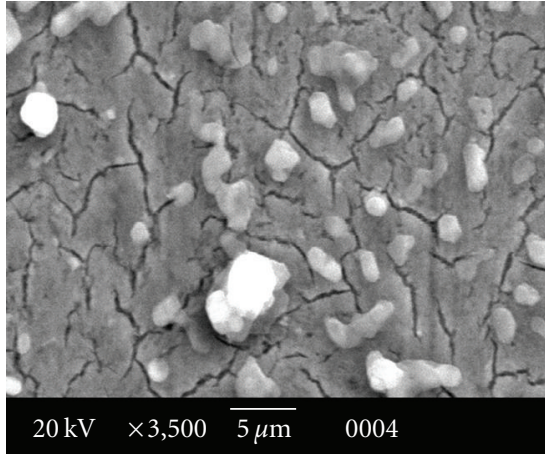

(a) Without induced charge

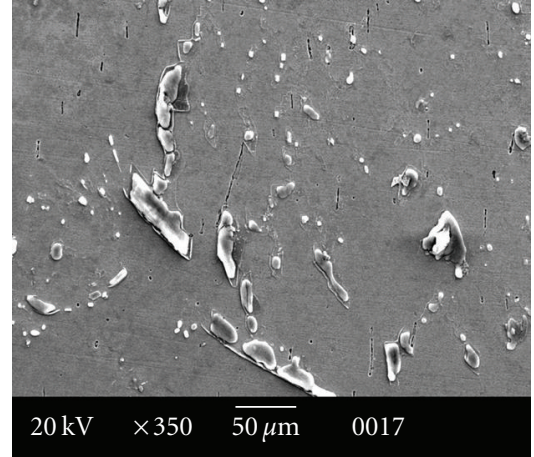

(b) With positive charge below pitting potential

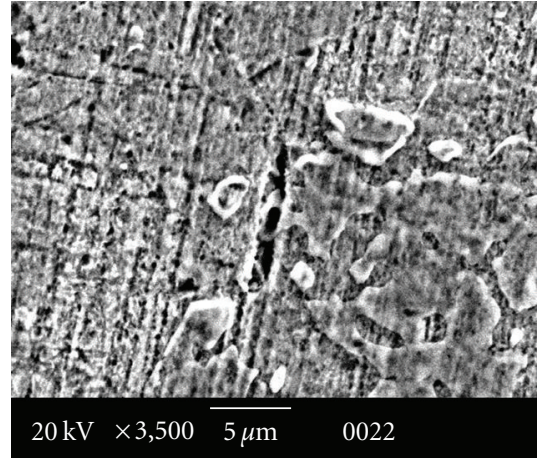

(c) With negative charge below pitting

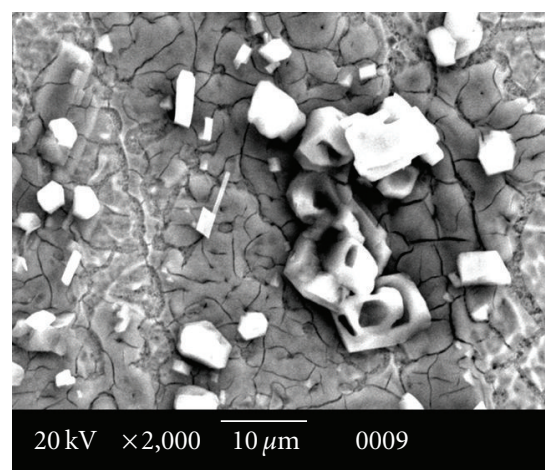

(d) With positive charge above pitting

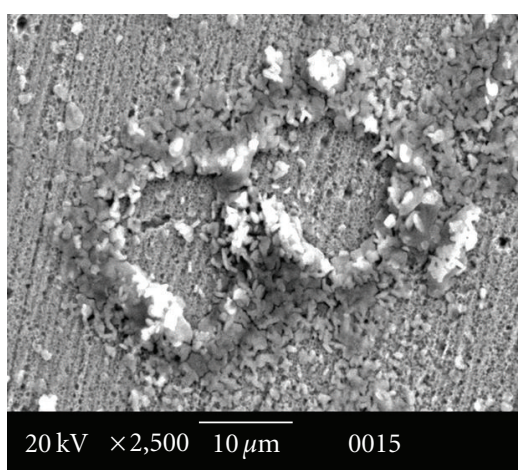

(e) With negative charge above pitting

FIGURE 8: SEM image in $0.2 \mathrm{~N} \mathrm{KCl}$ solution with and without induced charge.

It has been reported that below the pitting potential, there are negative charges on the oxide layer at which the $\mathrm{Cl}^{-}$ ions undergo contact adsorption. Above the pitting potential there are positive charges on the oxide layer, and hence the negative $\mathrm{Cl}^{-}$ions electrostatically adsorb more and more on the surface causing pitting corrosion. If positive electrostatic charges are supplied to the sample surface, then the following phenomenon may occur.

Since the pitting potential is considered as the point with zero charge, hence due to application of electrostatic positive charge on aluminium foil of the external circuit, there are induced negative charges on the surface of the working electrode. So, the $\mathrm{Cl}^{-}$ions preferentially move towards the aluminium foil. Hence, the anodic current on the potentiostatic circuit decreases.

Below the pitting potential, there are already negative charges on the oxide layer. Hence, with the application of the positive electrostatic charges on the aluminium foil, negative charge is further induced on the surface of the oxide surface of the working electrode, and therefore, the surface gets enriched with negative charges and repels the $\mathrm{Cl}^{-}$ions causing decrease in current as shown in the current transient curve 2 .

Above the pitting potential, there are positive charges on the oxide layer and hence the $\mathrm{Cl}^{-}$ions reaches the sample surface and tries to break the passive layer. But with the external positive charges on the aluminium foil, it was seen that the anodic current was lowered. It can be explained that the positive charges on the aluminium foil induced negative charges on the oxide surface, and if the induced charge is more than the previous charge present on the surface, the phenomenon is the same as happened below the pitting potential and hence current decreases as shown in the Figure 3.

In all the above cases, with the application of negative charges on the aluminium foil, the opposite phenomenon occurred and hence the anodic current increased as shown in Figures 2, and 3.

To further study the passive layer, electrochemical impedance spectroscopy was done with and without induced charge. Bode plot is used to determine the polarization resistance $\left(R_{p}\right)$ and the solution resistance $\left(R_{u}\right)$. The impedance spectra were analyzed using the equivalent electric circuits. For 304LN stainless steel with and without electrostatic charge in chloride solution, good fits were obtained with the constant phase element circuit. Constant phase element (CPE) implies a uniform passive layer arises due to the distribution of relaxation times resulting from the electrode surface. The fitted parameters are listed in the Tables 5, 6, and 7. From the Nyquist plots shown in Figures 4, 5, and 6, it can be noted that with the induced positive charge on the oxide surface, whether above and below the pitting potential polarisation, resistance increases. This indicates that the charge leaving the passive layer increases the corrosion 


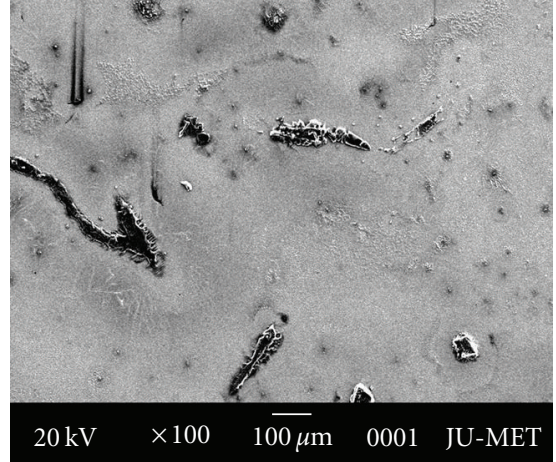

(a) Without induced charge

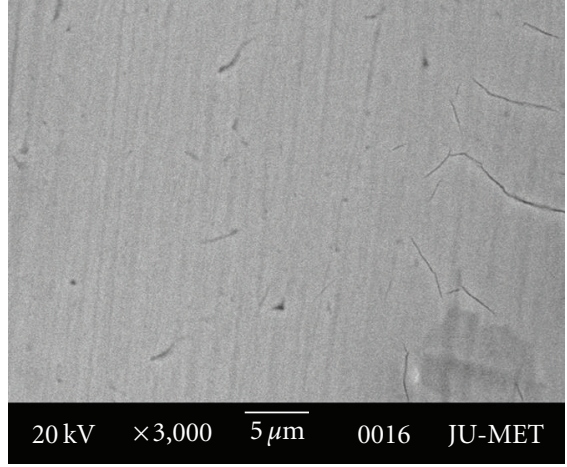

(b) With positive charge below pitting

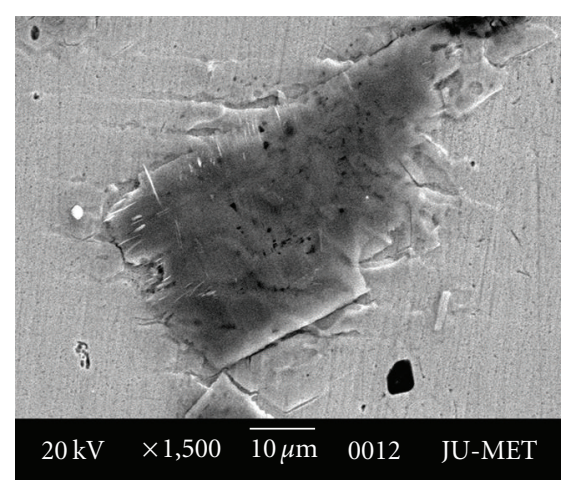

(c) With negative charge below pitting

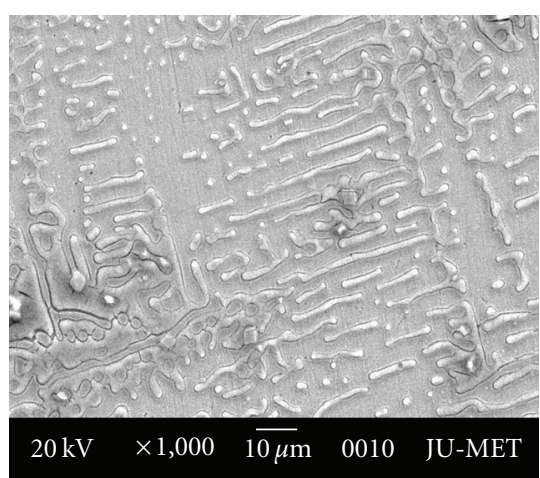

(d) With positive charge above pitting

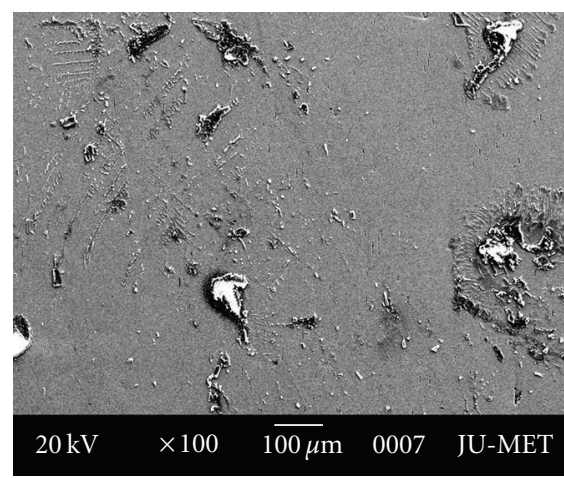

(e) With negative charge above pitting

Figure 9: SEM image in $0.25 \mathrm{~N} \mathrm{KCl}$ solution with and without induced charge.

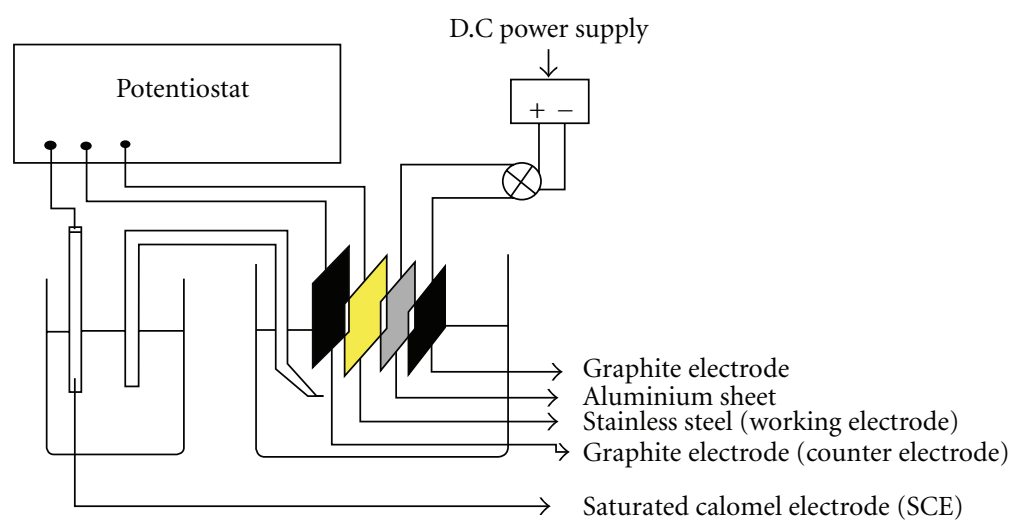

Figure 10

resistance property. The phase remains close to $-20^{\circ}$ to $-60^{\circ}$ over a wide range of frequency indicating a near capacitive response for all the alloys. This behaviour is indicative of a typical capacitive electrical double layer present on the surface. The $R_{p}$ value increases in every case irrespective of the chloride normality indicating that with the application of positive charge the oxide layer get thicker and the sample became more corrosion resistant.

SEM study of the passivated surfaces with and without external charge revealed contrasting microphotographs. For samples passivated above pitting potential without external charge (Figures 7(a), 8(a), and 9(a)), the oxide layer was found to be discontinuous and pits were also of larger diameter. On application of external positive charge; that is, with induced negative charge on the surface (Figures $7(d)$, $8(\mathrm{~d})$, and $9(\mathrm{~d}))$, the oxide layer became continuous and pit sizes were also finer.

Sample passivated below pitting potential showed continuous oxide layers irrespective of whether external charge was applied or not. However, with external positive charge, the morphology of the oxide layer changed. The oxide layer appeared to be more thicker (Figures 7(b), 8(b), and 9(b)). 


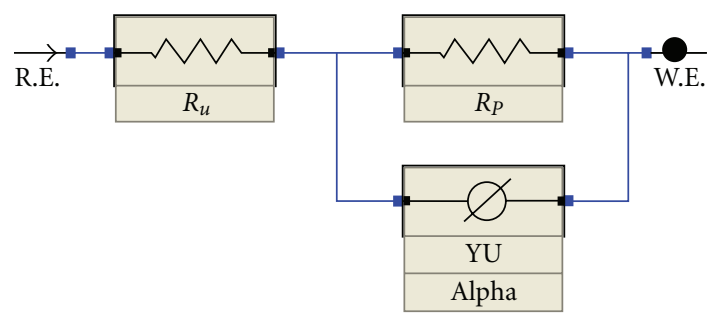

FIgURe 11

With the application of external negative charge, the oxide layers seemed to appear thinner and pitting seem to increase (Figures 7(e), 8(e), and 9(e)).

EDX analysis of the sample was performed for $1 \mathrm{NH} 2 \mathrm{SO} 4$ with 0.15 and $0.25 \mathrm{Cl}^{-}$ions. For $0.15 \mathrm{Cl}^{-}$, experiments were done below pitting potential, and for $0.25 \mathrm{Cl}^{-}$experiments were done above pitting potential. The data are given in Tables 8 , and 9, respectively. In general, there is an increase in chromium with application of charge. For experiments conducted below pitting potential for positive charge, there is almost no change in oxygen content suggesting, formation of chromium oxide, but oxygen content decreased with negative charges. However, for experiments conducted above pitting potential for both positive and negative charge application, there is decrease in oxygen signifying dissolution of oxide.

\section{Conclusion}

By applying positive charge on the aluminium foil of the external cell, corrosion on the working electrode stops for all practical purpose. Like cathodic protection, the external charging technique can, thus, be considered as additional method of protecting metals and alloys from corrosion.

Effect of positive and negative charging has no effect on $E_{\text {corr }}$ of the passivated samples in the respective solutions.

$I_{\text {corr }}$ of the passivated samples subjected to exposure and the charge on the nearby aluminium foil increased marginally in some cases, but no definite trend could be seen.

\section{References}

[1] J. M. Bastidas, M. F. López, A. Gutiérrez, and C. L. Torres, "Chemical analysis of passive films on type AISI 304 stainless steel using soft X-ray absorption spectroscopy," Corrosion Science, vol. 40, no. 2-3, pp. 431-438, 1998.

[2] Y. H. Kim, G. S. Frankel, J. C. Lippold, and G. Guaytima, "Development of a chromium-free consumable for austenitic stainless steels-part 1: monel (alloy 400) filler metal," Corrosion, vol. 62, no. 1, pp. 44-53, 2006.

[3] P. K. Mitra and S. C. Sircar, "A new method of measurement of pitting potential," in Proceedings of the 10th International Conference on Metallic Corrosion (ICMC '88), Madras, 1988.

[4] G. T. Burstein and G. O. Ilevbare, "The effect of specimen size on the measured pitting potential of stainless steel," Corrosion Science, vol. 38, no. 12, pp. 2257-2265, 1996.

[5] G. Bayaramoglu, T. Alemdaroglu, S. Kedici, and A. Aksut, "The effect of $\mathrm{pH}$ on the corrosion of dental metal alloys," Journal of Oral Rehabilitation, vol. 27, pp. 563-575, 2002. 

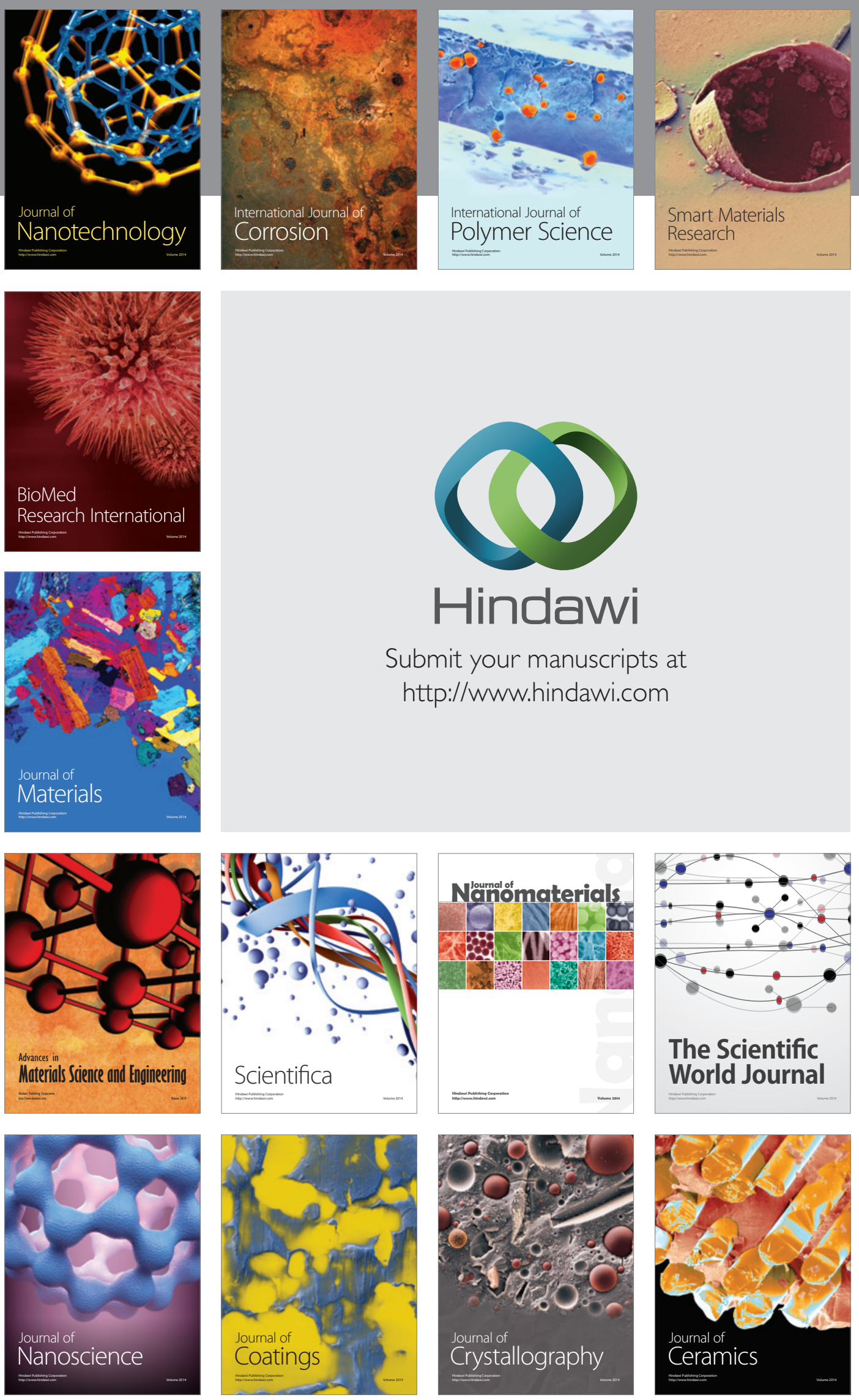

The Scientific World Journal

Submit your manuscripts at

http://www.hindawi.com

\section{World Journal}

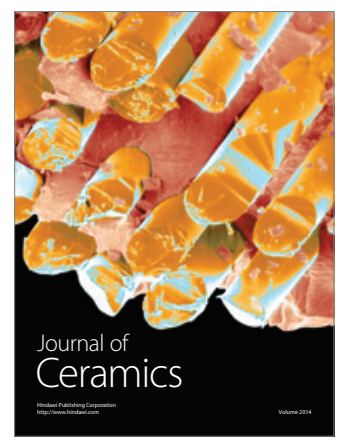

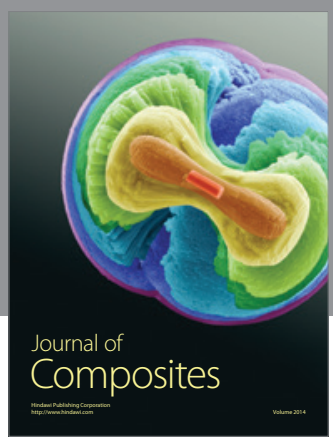
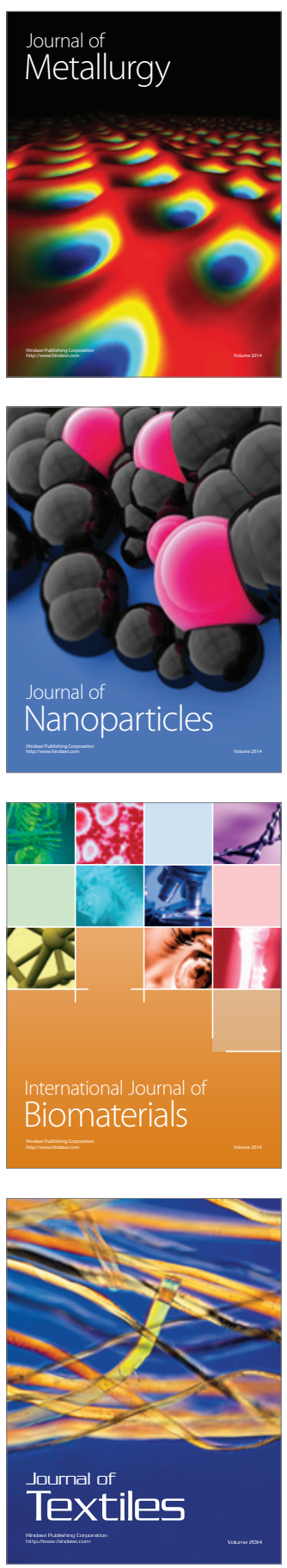